\title{
PENGARUH PENYUSUNAN POLARISASI PADA SISTEM ANTENA MIMO TERHADAP KAPASITAS KANAL
}

\author{
Abdurrahman Rizki ${ }^{1}$, Aloysius Adya Pramudita ${ }^{2}$, Trasma Yunita ${ }^{3}$ \\ 1, 2, ${ }^{3}$ Prodi S1 Teknik Telekomunikasi, Fakultas Teknik Elektro, Universitas Telkom, \\ Indonesia, 40257 \\ 1abdurahmanrizki@students.telkomuniversity.ac.id, \\ 2pramuditaadya@telkomuniversity.ac.id,3 trasmayunita@telkomuniversity.ac.id
}

\begin{abstract}
Abstrak
Sistem Multiple Input Multiple Output (MIMO) merupakan teknologi yang berpotensi untuk dikembangkan dalam meningkatkan kapasitas kanal. Peningkatan kapasitas kanal pada sistem MIMO tidak hanya ditentukan oleh jumlah antena, namun ditentukan oleh karakteristik dan konsep penyusunan antena. Penelitian ini melakukan identifikasi pengaruh penyusunan polarisasi circular pada sistem antena MIMO terhadap kapasitas kanal. Co-polarization terdiri dari konfigurasi Left Hand Circular Polarization (LHCP) dan Right Hand Circular Polarization (RHCP), sedangkan cross-polarization terdiri dari konfigurasi RHCP-LHCP. Antena co-polarization dengan konfigurasi LHCP menghasilkan estimasi kapasitas kanal 11,578 bps/Hz ketika berada pada Signal to Noise Ratio (SNR) terendah adalah 5 dB.
\end{abstract}

Kata Kunci: Antena, kapasitas kanal, MIMO, mutual coupling, polarisasi.

\section{Abstract}

Multiple Input Multiple Output (MIMO) system is a technology that has the potential to be developed to increase channel capacity. The increase in channel capacity in the MIMO system is not only determined by the number of antennas, but is determined by the characteristics and arrangement of the antenna concept. This study identifies the effect of circular polarization on the MIMO antenna system on channel capacity. Co-polarization consists of a Left Hand Circular Polarization (LHCP) and Right Hand Circular Polarization (RHCP) configuration, while cross-polarization consists of an RHCP-LHCP configuration. The co-polarization of the antenna with the LHCP configuration results in an estimated channel capacity of $11,578 \mathrm{bps} / \mathrm{Hz}$ when it is at the lowest Signal to Noise Ratio (SNR) is $5 \mathrm{~dB}$.

Key Words: Antenna, channel capacity, MIMO, mutual coupling, polarization.

\section{PENDAHULUAN}

Sistem Multiple Input Multiple Output (MIMO) merupakan teknologi yang berpotensi untuk dikembangkan dalam meningkatkan kapasitas kanal. Peningkatan kapasitas kanal pada sistem MIMO tidak hanya ditentukan oleh jumlah antena yang digunakan, namun ditentukan oleh karakteristik dan konsep penyusunan antena [1][2][3].

Perancangan antena MIMO mensyaratkan aspek mutual coupling yang rendah [4][5]. Merujuk bahwa mutual coupling antar elemen antena dipengaruhi oleh orientasi polarisasi antena, maka diperlukannya penyusunan polarisasi untuk mengurangi level coupling antar elemen pada antena MIMO [6] [7]. Penelitian awal [6] [7] menunjukkan bahwa penyusunan polarisasi akan memberikan dampak terhadap capaian kapasitas kanal dari sistem MIMO.
Masing-masing dari polarisasi tersebut mempunyai karakteristik yang berbeda salah satunya polarisasi circular memiliki Left Hand Circular Polarization (LHCP) dan Right Hand Circular Polarization (RHCP) [8].

Dalam hal ini penulis mengangkat topik mengenai Pengaruh Penyusunan Polarisasi pada Sistem Antena MIMO terhadap Kapasitas Kanal. Penyusunan polarisasi yang digunakan co-polarization konfigurasi LHCP dan RHCP. Sedangkan cross-polarization konfigurasi RHCP-LHCP. Spesifikasi antena menggunakan antena MIMO mikrostrip patch rectangular bekerja pada frekuensi $5,188 \mathrm{GHz}$ dengan menggunakan teknik corner truncated yang didesain menjadi delapan elemen. 


\section{KONSEP DASAR}

\subsection{Multiple Input Multiple Output (MIMO)}

Sistem Multiple Input Multiple Output (MIMO) adalah sistem penyusun lebih dari satu antena pada sisi pemancar ataupun sisi penerima dan biasanya ditulis dengan MIMO MN. Sistem MIMO merupakan pengembangan dari wireless 802.11ac [9].

Penggunaan sistem MIMO membutuhkan jarak antar antena, adapun perumusan untuk mendapatkan nilai jarak antar antena [10]:

$$
d=\frac{\lambda_{e r}}{2}
$$

$\lambda_{e r}$ adalah panjang gelombang pada bahan susbstrat, nilai $\lambda_{e r}$ dinyatakan dalam:

$$
\begin{aligned}
\lambda_{e r} & =\frac{\lambda_{0}}{\varepsilon_{r}} \\
\lambda_{0} & =\frac{c}{f_{0}}
\end{aligned}
$$

$\lambda_{0}$ adalah panjang gelombang diudara, $c$ adalah kecepatan cahaya diruang bebas dan $f_{0}$ adalah frekuensi kerja antena.

\subsection{Return loss}

Return loss adalah parameter yang digunakan untuk mengetahui berapa banyak daya yang hilang pada beban. Return loss terjadi karena impedansi saluran transmisi dan antena mismatched, serta didefinisikan dalam [11]:

$$
R L=-20 \log |\Gamma|
$$

$\Gamma$ adalah nilai koefisien pantul. Untuk matching antara transmitter dan antena, maka nilai $\Gamma=0$ yang berarti bahwa nilai return loss tidak ada daya yang dipantulkan. Apabila nilai $\Gamma=1$ maka semua daya dipantulkan [11].

\subsection{Mutual Coupling}

Perancangan antena MIMO mempertimbangkan mutual coupling rendah agar daya yang dipancarkan tidak diterima oleh antena sebelahnya dengan cara mengatur jarak antar antena, selain itu penyusunan polarisasi dapat mengurangi level coupling antar elemen pada sistem MIMO [7] dan mutual coupling diharapkan bernilai $\leq-20 \mathrm{~dB}$ [11]. Mutual coupling dapat dihitung dengan melihat besaran isolasi.

Isolasi merupakan perspektif sempit dari mutual coupling dan dapat dilihat dari masing-masing parameter mutual coupling. Sebagai contoh menghitung coupling dengan menggunakan $S_{2} 1$ seperti persamaan berikut [12]:

$$
M C=-10 \log _{10}\left|S_{21}\right|^{2}
$$

\subsection{Kapasitas Kanal}

Kapasitas kanal adalah kecepatan pengiriman suatu data maksimum dengan probabilitas error kecil [13]. Kapasitas kanal ditinjau dari nilai efisiensi spektral. Efisiensi spektral adalah jumlah dari banyak efisiensi pengirim data pada sebuah sel dalam jaringan selular dan satuannya bps/Hz. Perhitungan kapasitas kanal menggunakan perhitungan dari penelitian sebelumnya [14] [15]. Tahapan perhitungan kapasitas kanal meliputi:

1. Menghitung Z-Parameter

Perhitungan kapasitas kanal dimulai dengan menghitung matriks mutual impedance untuk antena transmitting $\left(Z_{t}\right)$ dan receiving $\left(Z_{r}\right)$ yang ditulis seperti [6]:

$$
Z_{t}=\left(\begin{array}{cccc}
1 & \frac{Z_{12}}{Z_{s 2}+Z 22} & \cdots & \frac{Z_{1 M}}{Z_{s M}+Z M M} \\
\frac{Z_{21}}{Z_{s 1}+Z 11} & 1 & \cdots & \frac{Z_{2 M}}{Z_{s M}+Z M M} \\
\vdots & \vdots & \ddots & \vdots \\
\frac{Z_{M 1}}{Z_{s 1}+Z 11} & \frac{Z_{M 2}}{Z_{s 2}+Z 22} & \cdots & 1
\end{array}\right)
$$

$Z_{s} m$ dan $Z_{m} m$ mewakili sumber impedansi dan self-impedance antena untuk elemen $m-t h$, sementara $Z_{t} m$ mewakili mutual impedance antara elemen $t-t h$ dan $m-t h$, dengan $m, t=1,2,, M . \quad M$ merupakan jumlah elemen dari transmitting array.

$$
Z r=\left(\begin{array}{cccc}
1 & \frac{-Z_{12}}{Z_{T}} & \cdots & \frac{-Z_{1 N}}{Z_{T}} \\
\frac{-Z_{21}}{Z_{T}} & 1 & \cdots & \vdots \\
\vdots & \vdots & \ddots & \vdots \\
\frac{-Z_{N 1}}{Z_{T}} & \frac{-Z_{N 1}}{Z_{T}} & \cdots & 1
\end{array}\right)
$$

$Z_{T}$ dan $Z_{t} n$ mewakili terminal impedance dan mutual coupling antara elemen $t-t h$ dan $n-t h$, dengan $n, t=1,2, ., N$ dan $N$ adalah jumlah elemen dari receiving array.

2. Menghitung Matriks Kanaldescription Setelah mendapatkan nilai dari matriks mutual impedance untuk antena transmitting $\left(Z_{t}\right)$ dan receiving $\left(Z_{r}\right)$ didapatkan, perhitungan dilanjutkan dengan menghitung matriks kanal dengan menggunakan [6]:

$$
H=Z_{r}^{-1} H_{S} Z_{t}^{-1}
$$

$H$ adalah matriks kanal yang dihitung dari invers matriks mutual impedance antena transmitting $\left(Z_{t}\right)$ dan receiving $\left(Z_{r}\right)$, dan matriks korelasi spasial $\left(H_{S}\right)$. Pada sistem multi-antenna terdapat kanal yang antar-kanalnya saling berkorelasi, hal ini disebut korelasi spasial $\left(H_{S}\right)$ yang dibentuk 
dalam persamaan:

$$
\begin{aligned}
\rho_{r_{m, n}}\left(d_{r-M, N}\right) & =j_{0}\left(d_{r-M, N}\right) \\
\rho t\left(d_{t-M, N}\right) & =j_{0}\left(d_{t-M, N}\right) \\
\rho_{h} & =\rho_{r_{m, n}} \bigotimes \rho_{t_{m, n}}
\end{aligned}
$$

$\rho_{t}(m, n)$ adalah matriks korelasi spasial di antena transmitter, sedangkan $\rho_{r}(m, n)$ adalah matriks korelasi spasial di antena receiver. Nilai eigen dan vektor eigen dari hasil operasi kronecker $\rho_{r} \otimes \rho_{t}$ dapat dihitung dengan persamaan:

$$
H_{s}=V \sqrt{D} r
$$

$V$ adalah bentuk matriks kolom dari $\rho_{r} \otimes \rho_{t}$, sedangkan $D$ adalah matriks diagonal dengan elemen diagonalnya adalah nilai eigen $\rho_{r} \otimes \rho_{t}$, dan $r$ adalah vektor yang berisi nilai kompleks random Gaussian yang bersifat Independent, and Identically Distributed (IID) dengan nilai mean $\mu=0$, dan mempertimbangkan unit variansi $\left(\sigma^{2}\right)$. Perhitungan kapasitas kanal pada dasarnya bersifat random karena sistem kanal dipengaruhi noise yang berbeda-beda disekitar lingkungannya. Model kanal random yang digunakan dalam pembentukkan model kanal $r$ dengan persamaan [14]:

$$
r=\sqrt{0.5}(\operatorname{randn}(N, M)+j \cdot \operatorname{randn}(N, M))
$$

$n$ adalah banyaknya sampel percobaan, $N$ adalah jumlah elemen dari receiving array dan $M$ adalah jumlah elemen dari transmitting array.

3. Menghitung Kapasitas Kanaldescription

Setelah mendapatkan nilai dari matriks kanal $(H)$ didapatkan, perhitungan dilanjutkan dengan menghitung kanal menggunakan [6]:

$$
C=E\left\{\log _{2} \operatorname{det}\left(1_{N r}+\frac{S N R}{M} H H^{\prime}\right)\right\}
$$

$C$ adalah kapasitas kanal MIMO dengan satuan bps/Hetz, $E$. adalah ekspektasi operasi, $I_{N} r$ adalah matriks identitas dari $N_{r} N_{r}$ dengan $N_{r}=\max (M, N)$, dan $S / N$ adalah signal to noise power ratio. Nilai efisiensi spektral yang terjadi bersifat ergodic. Hal ini dikarenakan nilainya berubah-ubah secara statistik.

\subsection{Polarisasi Circular}

Polarisasi circular dapat dicapai apabila magnitude sama namun waktu fasa berbeda. Axial ratio polarisasi circular dari $0<A R<3 \mathrm{~dB}$. Polarisasi circular saat $E_{x 0}=E_{y 0}$ maka [8]:

$$
\begin{aligned}
& \Delta \phi=\phi_{y}-\phi_{x}=+\frac{\pi}{2}(C W) \\
& \Delta \phi=\phi_{y}-\phi_{x}=-\frac{\pi}{2}(C C W)
\end{aligned}
$$

Apabila rotasi polarisasi bergerak clockwise (CW) maka polarisasinya Left Hand Circular Polarization (LHCP) [12], sedangkan rotasi polarisasi bergerak counter clockwise (CCW) maka polarisasinya Right Hand Circular Polarization (RHCP) [12].

\subsection{Metode Truncated}

Bentuk patch yang sederhana salah satunya patch rectangular, namun radiasi gelombangnya berpolarisasi liniear apabila menggunakan feed tanpa modifikasi [8]. Untuk mendapatkan polarisasi circular dilakukan dengan memodifikasi bentuk dan dimensi patch, yang membutuhkan pertubasi atau elemen pengganggu. Pertubasi yang digunakan yaitu corner truncated pada patch, dengan cara memotong kedua ujung pada patch [16].

Perpotongan sudut patch rectangular membentuk segitiga siku-siku dan perhitungannya menggunakan persamaan [17]:

$$
s=\sqrt{\Delta S}
$$

$\Delta S$ adalah luas dari perpotongan sudut antena. $\Delta S$ didapatkan dari [17]:

$$
\frac{\Delta s}{W}=\frac{1}{2 Q}
$$

$W$ adalah luas dari patch antena, sedangkan $Q$ adalah faktor kualitas patch antena. Untuk mencari faktor kualitas antena, didapatkan dengan persamaan berikut [17]:

$$
Q=\frac{f_{0}}{B W_{n}}
$$

$f_{0}$ merepresentasikan frekuensi tengah dari antena tanpa antena tanpa truncation dan $B W_{n}$ adalah bandwidth dari antena.

\section{$2.7 \quad 802.11 a c$}

802.11ac merupakan standarisasi jaringan Wi-Fi generasi kelima yang dikeluarkan oleh Institute of Electrical and Electronics Engineers (IEEE) [9] dan mendukung transmisi data diatas 1 Gbps. Secara umum, sinyal dengan Signal to Noise Ratio (SNR) yang direkomendasikan untuk data network yaitu 20 $\mathrm{dB}$ atau lebih. Spesifikasi dari jaringan 802.11ac beroperasi sub $5 \mathrm{GHz}$ yang mengakibatkan lebih sedikit interference dari Wi-Fi sekitar, selain itu berkemampuan Multi User-Multiple Input Multiple Output (MU-MIMO) [9].

\section{PERANCANGAN}

\subsection{Skenario Penelitian}

Penelitian ini difokuskan pada identifikasi pengaruh penyusunan polarisasi circular dengan mempertimbangan mutual coupling antar elemen antena untuk melihat pengaruhnya terhadap kapasitas 


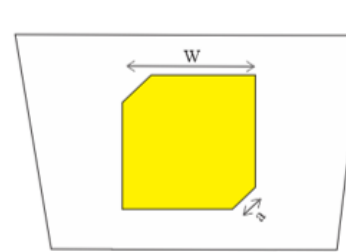

(a)

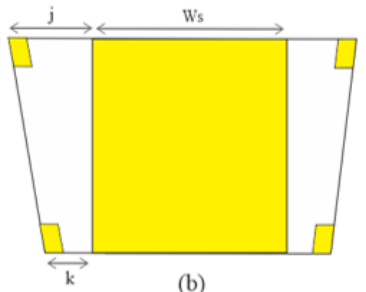

(b)
Gambar 1. Desain antena tampak depan dan tampak belakang

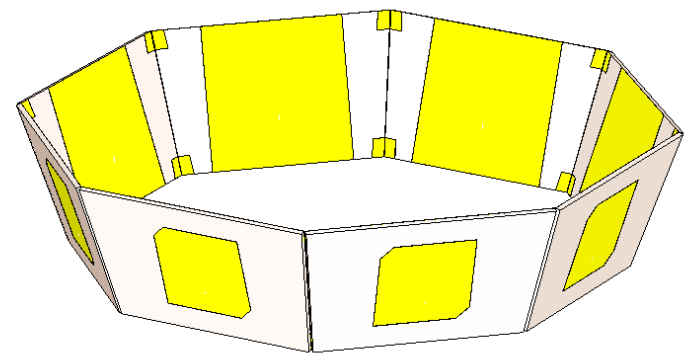

Gambar 2. Desain antena delapan elemen

kanal. Pemilihan polarisasi circular karena posisi Left Hand Circular Polarization (LHCP) dan Right Hand Circular Polarization (RHCP) yang orthogonal dapat dimanfaatkan untuk menggandakan kapasitas kanal link, selain itu penyusunan polarisasi dapat mengurangi coupling antar elemen antena Multiple Input Multiple Output (MIMO). Dalam perancangan antena, spesifikasi bahan yang digunakan patch dan groundplane adalah copper dengan ketebalan 0,035 $\mathrm{mm}$, substrat menggunakan Roger Duroid RO4003C dengan ketebalan $0,813 \mathrm{~mm}, \varepsilon_{r}=3,38$.

\section{Tabel 1. Spesifikasi antena}

\begin{tabular}{|l|l|}
\hline Spesifikasi & Deskripsi \\
\hline Jenis antena & Antena MIMO \\
\hline Bentuk antena & Rectangular $($ corner truncated $)$ \\
\hline Frekuensi kerja & $5,150 \mathrm{s.d} 5,825 \mathrm{GHz}$ \\
\hline Mutual Coupling & $\leq-20 \mathrm{~dB}$ \\
\hline Polarisasi & $\mathrm{LHCP} / \mathrm{RHCP}(\mathrm{AR} \leq 3 \mathrm{~dB}$ \\
\hline Return loss & $\leq-10 \mathrm{~dB}$ \\
\hline
\end{tabular}

\subsection{Desain Antena}

Desain antena yang dirancang menggunakan antena delapan elemen, hal ini dikarenakan untuk membuat antena memiliki pola radiasi ke segala arah (omnidirectional) seperti Gambar 2. Gambar 1 merupakan desain antena tampak depan dan tampak belakang.

Antena yang dirancang memiliki co-polarization konfigurasi LHCP dan RHCP seperti Gambar 3.
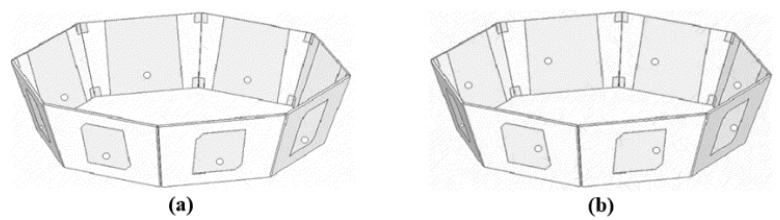

Gambar 3. Co-polarization konfigurasi (a) LHCP, (b) RHCP

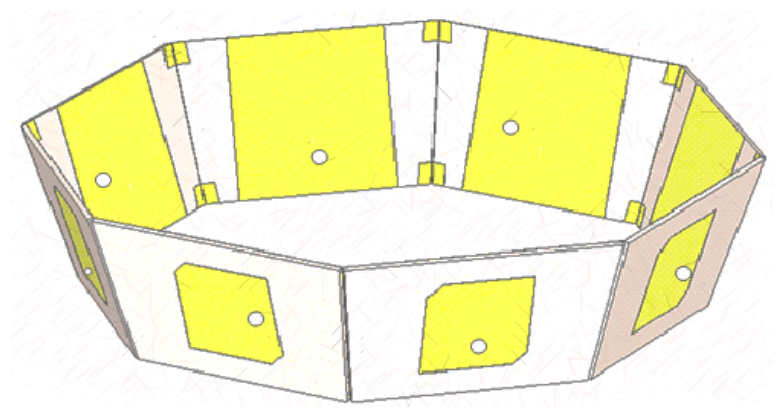

Gambar 4. Cross-polarization konfigurasi RHCP-LHCP

Sedangkan cross-polarization seperti Gambar 4. Orientasi polarisasi tersebut didapatkan dari peletakkan port diletakkan berdasarkan sumbu $\mathrm{X}$ dan sumbu Y. Konfigurasi LHCP diletakkan pada sumbu Y negatif, sedangkan konfigurasi RHCP diletakkan pada sumbu X positif.

\subsection{Hasil Simulasi Ketiga Konfigurasi}

Perbandingan dari ketiga konfigurasi diambil dari return loss dan sampel mutual coupling. Perbandingan ini digunakan sebagai acuan dalam memilih salah satu konfigurasi polarisasi terbaik berdasarkan mutual coupling yang terendah. Tabel 2 adalah nilai return loss dari konfigurasi LHCP, RHCP, dan RHCP-LHCP. Berdasarkan nilai dari tabel ditunjukkan bahwa hasil dari cross-polarization lebih rendah dibandingan co-polarization, akan tetapi nilai dari return loss ketiga konfigurasi tersebut memenuhi spesifikasi batas dari return loss yaitu $\leq-10 \mathrm{~dB}$.

Tabel 3 adalah sampel $M C_{21}$ dari konfigurasi LHCP, RHCP dan RHCP-LHCP. Berdasarkan dari tabel tersebut dapat dilihat bahwa cross-polarization mempunyai nilai mutual coupling lebih rendah dibanding co-polarization.

Hasil dari konfigurasi tersebut sesuai dengan teori dan penelitian [6] [7] yang menyatakan bahwa penyusunan polarisasi mengarah pada coupling yang rendah dengan menunjukkan bahwa mutual coupling cross-polarization lebih rendah daripada co-polarization karena pada antena MIMO cross-polarization polarisasi yang dihasilkan saling orthogonal, maka Polarization Loss Factor (PLF) 
Tabel 2. Perbandingan return loss LHCP, RHCP dan RHCP-LHCP.

\begin{tabular}{|c|c|c|c|}
\hline \multirow{2}{*}{$\begin{array}{c}\text { Return } \\
\text { loss }\end{array}$} & \multicolumn{2}{|c|}{ Co-polarization } & \multirow{2}{*}{$\begin{array}{c}\begin{array}{c}\text { Cross- } \\
\text { polarization }\end{array} \\
\text { RHCP- } \\
\text { LHCP } \\
\text { (dB) }\end{array}$} \\
\hline & $\begin{array}{c}\text { LHCP } \\
\text { (dB) }\end{array}$ & $\begin{array}{c}\text { RHCP } \\
(\mathbf{d B})\end{array}$ & \\
\hline$R L_{11}$ & -10.412 & -18720 & -19.343 \\
\hline$R L_{22}$ & -17.672 & -14.943 & -16.872 \\
\hline$R L_{33}$ & -10.430 & -18.720 & -18.150 \\
\hline$R L_{44}$ & -17.760 & -14.904 & -18.075 \\
\hline$R L_{55}$ & -10.661 & -18.790 & -18.225 \\
\hline$R L_{66}$ & -19.282 & -14.856 & -20.237 \\
\hline$R L_{77}$ & -10.714 & -18.797 & -19.254 \\
\hline$R L_{88}$ & -19.204 & -14.909 & -15.176 \\
\hline
\end{tabular}

Tabel 3. Perbandingan sampel mutual coupling $S_{21}$ LHCP, RHCP dan RHCP-LHCP.

\begin{tabular}{|c|c|c|c|}
\hline \multirow{2}{*}{$\begin{array}{c}\text { Mutual } \\
\text { Coupling } \\
\text { (MC) }\end{array}$} & \multicolumn{2}{|c|}{ Co-polarization } & \multirow{2}{*}{$\begin{array}{c}\begin{array}{c}\text { Cross- } \\
\text { polarization }\end{array} \\
\text { RHCP- } \\
\text { LHCP } \\
\text { (dB) }\end{array}$} \\
\hline & $\begin{array}{c}\text { LHCP } \\
\text { (dB) }\end{array}$ & $\begin{array}{c}\text { RHCP } \\
\text { (dB) }\end{array}$ & \\
\hline$M C_{21}$ & -35.647 & -29.203 & -35.194 \\
\hline$M C_{31}$ & -43.777 & -44.736 & -45.576 \\
\hline$M C_{41}$ & -43.693 & -45.701 & -46.583 \\
\hline$M C_{51}$ & -42.169 & -39.494 & -38.706 \\
\hline$M C_{61}$ & -43.448 & -44.682 & -47.059 \\
\hline$M C_{71}$ & -43.870 & -4.729 & -45.338 \\
\hline$M C_{81}$ & -34.385 & -28.893 & -32.779 \\
\hline
\end{tabular}

sama dengan nol dan tidak ada daya yang diterima antar elemen. Maka dipilih antena MIMO cross-polarization konfigurasi RHCP-LHCP sebagai antena yang difabrikasi.

\section{ANALISIS}

\subsection{Analisis Kapasitas Kanal}

Penelitian ini menggunakan software untuk mendapatkan data dari antena yang dirancang dan perhitungan kapasitas kanal. Konfigurasi yang digunakan yaitu co-polarization (LHCP, RHCP), cross-polarization (RHCP-LHCP) yang didapat dari hasil simulasi dan without polarization setting. Maksud dari without polarization setting adalah kondisi ideal yang hanya menggunakan perhitungan jarak dari masing-masing elemen antena tanpa memperhitungkan S-Parameter. Identifikasi kapasitas kanal yang dilakukan dengan membandingkan konfigurasi LHCP, RHCP (co-polarization) dan RHCP-LHCP (cross-polarization). Tabel 4 adalah perbandingan efisiensi spektral co-polarization, cross-polarization dan without polarization setting. Ketika kondisi without polarization setting menghasilkan nilai rata-rata sebesar $24,240 \mathrm{bps} / \mathrm{Hz}$ dengan SNR terendah $5 \mathrm{~dB}$ yaitu $11,576 \mathrm{bps} / \mathrm{Hz}$ dan tertinggi $20 \mathrm{~dB}$ yaitu 39,069 bps/Hz, kondisi ini adalah kondisi ideal yang hanya menggunakan perhitungan jarak antar elemen antena.

Tabel 4. Perbandingan efisiensi spektral co-polarization, cross-polarization dan without polarization setting.

\begin{tabular}{|c|c|c|c|c|}
\hline \multirow{2}{*}{$\begin{array}{l}S N R \\
(d B)\end{array}$} & \multicolumn{2}{|c|}{ Co-polarization } & \multirow{2}{*}{$\begin{array}{c}\text { Cross- } \\
\text { polari } \\
\text { zation } \\
\text { RHCP- } \\
\text { LHCP } \\
\text { (dB) }\end{array}$} & \multirow{2}{*}{$\begin{array}{l}\text { Without } \\
\text { Polari- } \\
\text { zation } \\
\text { Setting }\end{array}$} \\
\hline & $\begin{array}{c}\text { LHCP } \\
(\mathrm{dB})\end{array}$ & $\begin{array}{c}\text { RHCP } \\
\text { (dB) }\end{array}$ & & \\
\hline 5 & 11.578 & 11.504 & 11.565 & 11.576 \\
\hline 6 & 12.920 & 12.856 & 12.916 & 12.926 \\
\hline 7 & 14.356 & 14.291 & 14.338 & 14.371 \\
\hline 8 & 15.874 & 15.804 & 15.859 & 15.882 \\
\hline 9 & 17.461 & 17.387 & 17.442 & 17.458 \\
\hline 10 & 19.117 & 19.051 & 19.118 & 19.123 \\
\hline 11 & 20.836 & 20.776 & 20.943 & 20.854 \\
\hline 12 & 22.649 & 22.580 & 22.638 & 22.649 \\
\hline 13 & 24.498 & 24.439 & 24.499 & 24.572 \\
\hline 14 & 26.427 & 26.361 & 26.432 & 26.443 \\
\hline 15 & 28.400 & 28.337 & 28.401 & 28.415 \\
\hline 16 & 30.443 & 30.379 & 30.434 & 30.465 \\
\hline 17 & 32.539 & 32.474 & 32.525 & 32.536 \\
\hline 18 & 34.673 & 34.620 & 34.657 & 34.674 \\
\hline 19 & 36.840 & 36.786 & 36.845 & 36.852 \\
\hline 20 & 39.072 & 39.026 & 39.056 & 39.069 \\
\hline $\begin{array}{l}\text { Ave- } \\
\text { rage }\end{array}$ & 24.230 & 24.167 & 24.223 & 24.240 \\
\hline
\end{tabular}

Dari Tabel 4, diketahui bahwa efisiensi spektral yang dihasilkan antena co-polarization konfigurasi LHCP memiliki hasil efisiensi spektral lebih baik daripada co-polarization konfigurasi RHCP dan cross-polarization walaupun perbedaan antara ketiga konfigurasi tersebut tidak signifikan. Hal ini disebabkan oleh pengaruh dari nilai S-Parameter (return loss dan mutual coupling). Kapasitas kanal akan meningkat apabila nilai return loss dan mutual coupling diperhatikan, apabila salah satu parameter nilainya tidak maksimal maka kapasitas kanal tidak maksimal. Dari penelitian ini, dapat disimpulkan bahwa pengaturan polarisasi berdampak pada kapasitas kanal. 


\section{KESIMPULAN}

Terkait dengan penelitian ini disimpulkan bahwa penyusunan polarisasi perlu dilakukan dengan mempertimbangkan nilai return loss dan mutual coupling serendah mungkin karena akan memberikan dampak pada estimasi kapasitas kanal. Mutual coupling terendah yaitu cross-polarization, hal ini karena polarisasi yang dihasilkan saling orthogonal, maka Polarization Loss Factor (PLF) sama dengan nol dan tidak ada daya yang diterima antar elemen. Hasil efisiensi spektral co-polarization konfigurasi LHCP menghasilkan nilai rata-rata sebesar 24,230 $\mathrm{bps} / \mathrm{Hz}$ dengan SNR terendah $5 \mathrm{~dB}$ yaitu $11,578 \mathrm{bps} / \mathrm{Hz}$ dan tertinggi $20 \mathrm{~dB}$ yaitu $39,073 \mathrm{bps} / \mathrm{Hz}$.

\section{Daftar Pustaka}

[1] D. W. Bliss, K. W. Forsythe, and A. M. Chan, "Mimo wireless communication," Lincoln Laboratory Journal, vol. 15, no. 1, pp. 97-126, 2005.

[2] T. L. Marzetta, "Massive mimo: an introduction," Bell Labs Technical Journal, vol. 20, pp. 11-22, 2015.

[3] F. De Flaviis, L. Jofre, J. Romeu, and A. Grau, "Multiantenna systems for mimo communications," Synthesis Lectures on Antennas, vol. 3, no. 1, pp. 1-250, 2008.

[4] X. Liu, M. Bialkowski, and F. Wang, "Investigation into the effects of spatial correlation on mimo channel estimation and capacity," in 2008 4th International Conference on Wireless Communications, Networking and Mobile Computing. IEEE, 2008, pp. 1-4.

[5] J. W. Wallace and M. A. Jensen, "Mutual coupling in mimo wireless systems: A rigorous network theory analysis," IEEE transactions on wireless communications, vol. 3, no. 4, pp. 1317-1325, 2004.

[6] E. Susanti, A. Pramudita, M. M. Rose et al., "Mimo antenna with cross polarisation printed yagi elements for mimo router," in 2017 3rd International Conference on Wireless and Telematics (ICWT). IEEE, 2017, pp. 65-69.
[7] A. Pramudita, D. D. Ariananda et al., "Array of eight circularly polarized microstrip antennas for ieee 802.11 ac mimo wlan," in 2018 4th International Conference on Science and Technology (ICST). IEEE, 2018, pp. 1-6.

[8] C. A. Balanis, Antenna theory: analysis and design. John wiley \& sons, 2016.

[9] Cisco. Cisco System Inc, 2018, p. 1.

[10] A. Sibille, C. Oestges, and A. Zanella, MIMO: from theory to implementation. Academic Press, 2010.

[11] A. D. Purnamasari, R. P. Astuti, and B. S. Nugroho, "Perancangan dan analisis antena massive mimo mikrostrip patch persegi panjang dengan polarisasi linier untuk komunikasi 5g (28 ghz)," eProceedings of Engineering, vol. 4, no. 3, 2017.

[12] D. M. Pozar, "Microwave engineering," Fourth Editions, University of Massachusetts at Amherst, John Wiley \& Sons, Inc, pp. 26-30, 2012.

[13] W. Middleton and M. E. Van Valkenburg, "Reference data for engineers: Radio, electronics," Computer, and Communications. Number ISBN-10, vol. 750672919, 2002.

[14] X. Li and Z.-P. Nie, "Mutual coupling effects on the performance of mimo wireless channels," IEEE antennas and wireless propagation letters, vol. 3, pp. 344-347, 2004.

[15] X. Liu and M. E. Bialkowski, "Effect of antenna mutual coupling on mimo channel estimation and capacity," International Journal of Antennas and Propagation, vol. 2010, 2010.

[16] M. Shakeeb, H. Hammad, and A. Sebak, "Comprehensive study of single feeding techniques on circularly polarized microstrip antenna radiation pattern," in IEEE Middle East Conference on Antennas and Propagation (MECAP 2010). IEEE, 2010, pp. 1-5.

[17] R. A. Sainati, CAD of microstrip antennas for wireless applications. Artech House, Inc., 1996. 